\title{
CLINICAL AND RADIOLOGICAL ASPECTS OF CALCIFICATION OF THE MITRAL REGION
}

\author{
BY \\ EINO LINKO AND ERKKI SYSIMETSÄ \\ From the Medical Clinic and the Cardio-Respiratory Research Unit, University of Turku,
Finland \\ Received September 20, 1957
}

Calcification of the cardiac valves and adjacent tissues has long been known to both clinicians and pathologists. Previous rheumatic endocarditis has been considered the cause of the calcification, and this is of clinical importance. The incidence of calcification associated with rheumatic valvular disease has been examined on the basis of autopsy findings by Epstein (1940) among others; he found calcification that varied in size from microscopically small particles to large calcareous masses in 64 out of 148 cases. This calcification not only involves the cardiac valve leaflets, but may also appear in the annulus fibrosus, the wall of the left atrium, and the papillary muscles. Similar calcification may develop without previous rheumatic infection, especially after middle age. Simon and Liu (1954) found calcification of the mitral valve annulus in 10 per cent of 590 unselected, consecutive autopsies and, like some others, observed that the incidence increased with age.

The occurrence of calcification within the heart at X-ray examination was noted fairly early. Thus, for instance, Klason (1921) described a case of partial calcification of the mitral ring observed by fluoroscopy. Saul (1932) was apparently the first to publish X-ray pictures of three cases of this kind. Subsequently isolated cases or small series have been reported (e.g. Sossman and Wosika, 1933; Bishop and Roessler, 1934; Baumann, 1936; and Sundberg, 1941).

Most investigators consider radioscopy more trustworthy than radiography for the detection of intracardial calcifications. This is natural since calcification that is frequently present in the lungs, hila, or rib cartilages produces shadows in the region of the heart valves and cannot be readily distinguished from calcification of the valves. In radioscopy, however, the valvular calcification differs in mobility from the extra-cardiac calcification since the former moves with the cardiac rhythm and the latter with respiration. However, the subjectiveness and other secondary factors often reduce the reliability of radioscopic observation.

The progress made in recent years in heart surgery has reawakened interest in the problem of the calcification of mitral valves and of the annulus fibrosus. Mitral valve calcification is frequently encountered in connection with cardiac operations, according to Bailey and Morse (1957) with an incidence of 42 per cent. Opinions about the significance of mitral valve calcification as a contra-indication to surgery and as a factor influencing the results of mitral valvotomy seem, however, to be divergent.

Since it is the duty of a physician not only to make a clinical diagnosis of valvular disease but also to express an opinion about any contra-indications, numerous investigators have stressed the importance of a thorough radiological examination of the heart, particularly to detect calcification. Radioscopy has been used generally in such examinations and it has its strong points, but sometimes calcification can be recognized also in ordinary films. These have been used, for instance, by Wynn (1953) in an extensive study of the incidence of calcification in mitral valvular disease of various clinical types. 
In recent years tomography has gained more and more favour alongside the above methods of investigation. Hohenner (1940) was apparently the first to present a tomogram showing a partially calcified mitral ring. The superiority of tomography has been particularly stressed by Soloff et al. $(1954,1955)$ since with its aid it is possible to determine more reliably the extent of the calcification: in their 16 patients with mitral stenosis, they found valvular calcification in twelve.

The aim of the present study was to examine by means of simultaneous tomography the region of the mitral valve in patients with clinically proved mitral disease and to correlate the findings with clinical observations for the evaluation of indications for surgery.

\section{MATERIAL AND MethodS}

The series comprised 68 consecutive unselected patients with rheumatic mitral and/or aortic valvular disease of varying degree of clinical severity who were being treated or examined at the University Medical Clinic in Turku.

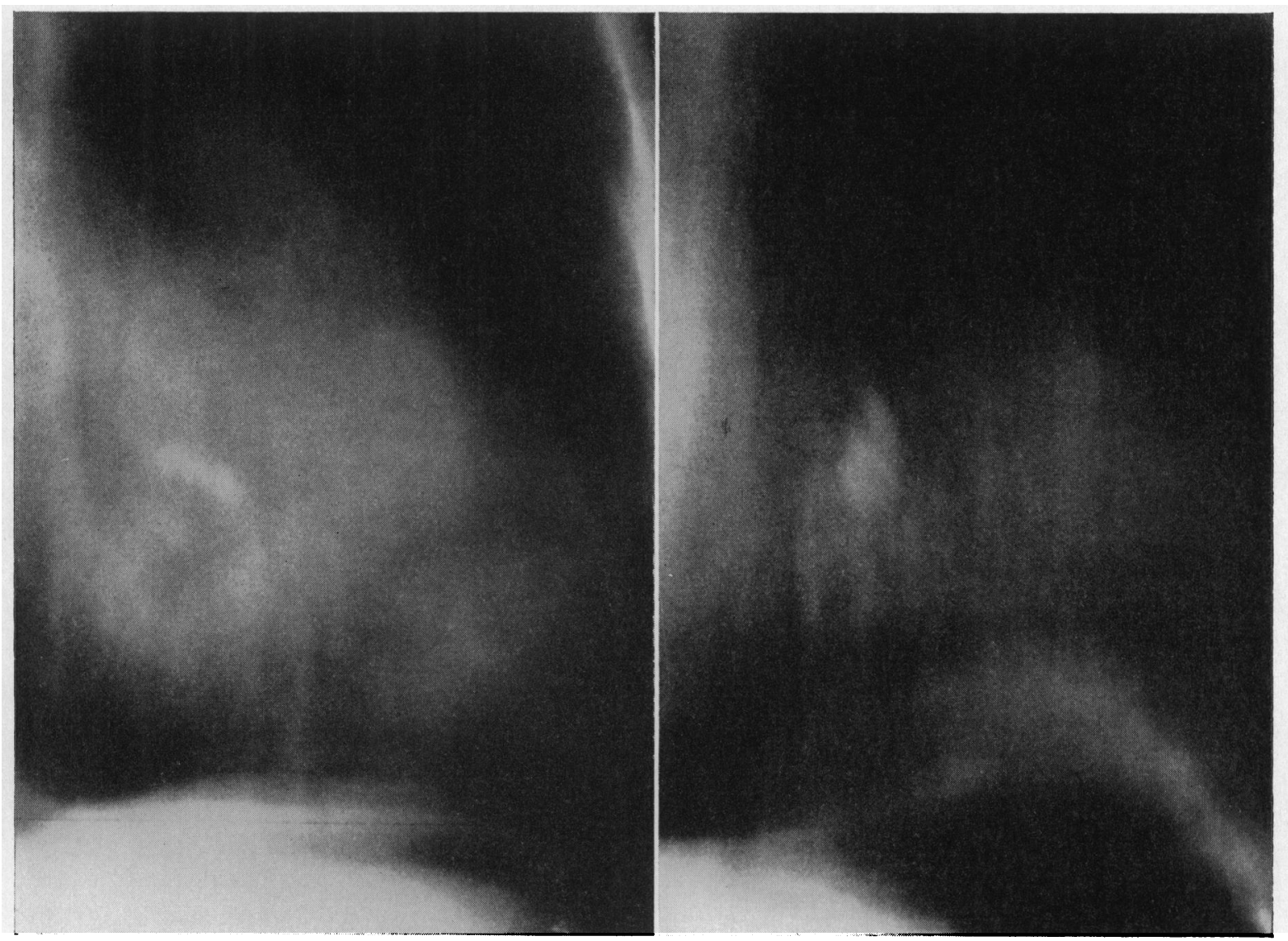

FIG. 1.- Tomography in right oblique projection shows a pro- FIG. 2.-Tomography in slight right oblique projection nounced calcified area about $1 \times 2 \mathrm{~cm}$. in the region of the mitral valve, about $4 \mathrm{~cm}$. ventral to the left posterior wall of the heart. A man, aged 53 years. Slight dyspnœa in 1944, and more severe in 1945 . Treated in hospital with diagnosis of mitral regurgitation and atrial fibrillation. reveals partial calcification of the mitral annulus about $3.5 \mathrm{~cm}$. in diameter, $4 \mathrm{~cm}$. ventral to the left posterior wall of the heart. A woman, aged 33 years. Polyarthritis about ten years previously. Irregular heart action on exertion during the last eighteen months, and dyspnœa during the past six months. No treatment before admission to hospital with a diagnosis of mitral stenosis. 
The routine cardiological examination consisted in most cases of a phonocardiographic confirmation of the auscultation findings, a 12-lead electrocardiogram, a thorough radiological examination of the heart in which particular attention was paid to the relative magnitudes of the left atrium and left ventricle, and a measurement of the cardiac volume.

Tomography. The tomograms were recorded in a slightly right anterior oblique projection (about 20 degrees). When this projection is used the various cardiac valves are not superimposed to the same extent as when the angle is $\mathbf{4 0}$ degrees and can be more easily distinguished from each other, and furthermore the shadow of the spine is not projected on the shadows of the valves as in tomograms taken in the posterioranterior direction. Also the thickness of the object is not magnified to the same extent as in a tomogram taken in the normal oblique direction. The shadows of the valves could be differentiated best in a tomogram taken in the left oblique projection, but the angle must then be at least 45 degrees before the shadow of the spine can be eliminated, and then the thickness of the heart and the object will reduce the contrast so much that we have found it preferable to use an angle of 20 degrees as mentioned above.

The recordings were made with a Siemens Universal tomograph with the patient in the standing position, with the following exposure data: $250 \mathrm{~mA}(2.5$ seconds), $80-100 \mathrm{kV}$, distance $150 \mathrm{~cm}$. The tomograms were taken with a Siemens simultaneous cassette (7 exposures at $1-\mathrm{cm}$. distances). The good features of this cassette were shown well in this type of recording: the adjustment is easily made and a series of exposures are obtained from a region $7 \mathrm{~cm}$. thick and consequently the amount of radiation the patient is exposed to is considerably smaller than when single tomograms are taken. There is also the advantage that the examination does not tire the patient excessively and requires less time.

\section{RESULTS}

For the sake of brevity, the extent and intensity of the calcifications are graded as follows.

$$
\begin{aligned}
& \text { Slight }(+) \quad \ldots \quad \text {. . } \quad \text { Small, diffuse calcified areas in the valves. } \\
& \text { Moderate }(++) \quad \text {. } \quad \text { Clearly discernible calcification in the valve leaflets seen at }
\end{aligned}
$$

The tomograms of 24 of the 68 patients examined revealed calcification which varied in severity as follows: slight in 6, moderate in 10, and severe in 8 cases. In only one of these patients was the existence of calcification established with certainty by ordinary X-ray examination.

\section{Correlation with Clinical Findings}

By examining the past histories of the patients, the time since the onset of the rheumatic infection that caused the valvular disease could be determined with a high degree of certainty in 50 patients (Table I). It was observed that no calcification had developed if this time was less than ten years. When the time was longer, no clear differences were noted between time groups although calcification was observed in 5 of 6 patients where the time was over 30 years. In these cases factors associated with their age, apart from the time since their rheumatic endocarditis, may have exerted an effect. No correlation was established between the extent of the calcification and the length of time since the infection.

As regards the correlation between the age of a patient and the incidence of calcification, none of the patients under 30 had any calcification and the older age groups showed no difference in incidence (Table II).

On the basis of the clinical findings and special investigations, the material could be divided into groups as shown in Table III. The greatest relative incidence of calcification of the mitral area occurred in the group in which the stenosis was dominant and the incidence was much less in those where the regurgitation was dominant. The other groups are too small to permit any conclusions.

A closer examination of the group of 21 cases of mitral stenosis revealed that in 11 the clinical status and other findings pointed to the advisability of surgery (auricular fibrillation and age of the patient have been considered only relative contraindications): in four of these eleven the mitral valve 
TABLE I

InCidence of CALCification According to Time from Onset of Rheumatic InfeCtion

\begin{tabular}{c|c|c|c|c}
\hline Years & 10 or less & $11-20$ & $21-30$ & 31 or more \\
\hline $\begin{array}{c}\text { Patients with calcification } \\
\text { Patients with no calcification }\end{array}$ & 0 & 7 & 5 & 5 \\
\hline
\end{tabular}

TABLE II

Influence of Age on the Presence of Calcification

\begin{tabular}{|c|c|c|c|}
\hline Age in years & 30 or less & $31-40$ & 41 or more \\
\hline $\begin{array}{l}\text { Number with calcification } \\
\text { Number with no calcification }\end{array}$ & $\begin{array}{r}0 \\
19\end{array}$ & $\begin{array}{r}9 \\
10\end{array}$ & $\begin{array}{l}15 \\
15\end{array}$ \\
\hline
\end{tabular}

TABLE III

Influence of the Valve Lesion on the Presence of Calcification

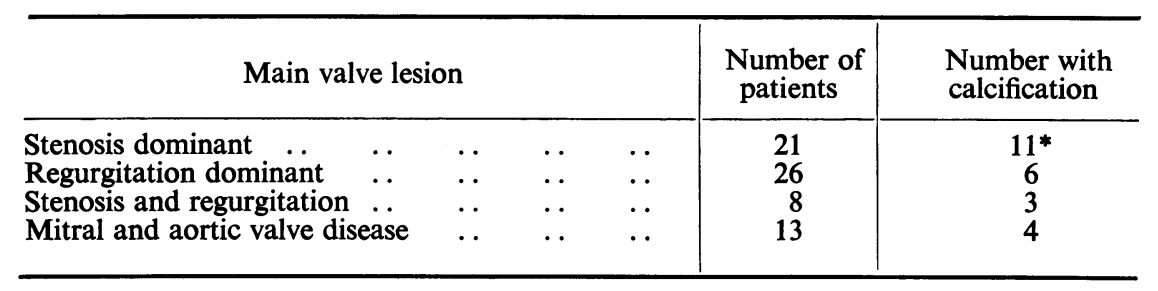

* In one case pulmonary stenosis of the valvular type was also established by right heart catheterization

and/or the annulus fibrosus were detectably calcified. Of the remaining 10 the reduction in functional capacity was so slight (Class I) in two that immediate surgery was not indicated and no calcification was evident. Four further patients belonged to Classes II and III, but other diseases contra-indicated surgery; three of these had calcification. The remaining four belonged to Class IV with absolute contra-indications to surgical intervention: all these showed calcification of higher order $(t+t)$.

\section{Discussion}

It is of interest that increasing attention has been paid recently to mitral calcification from the surgical angle also. This may be due to the fact that the range of indications has been continuously extended as far as age is concerned, but it should also be remembered that calcification in the mitral area is not unusual even in young persons (e.g. Wynn, 1953). In children calcification is extremely rare, although severe stenosis may occur (Nadas, 1957).

The effect of calcification on the function of the mitral valve has been discussed, and, for instance, Wynn (1953) concluded that gross calcification of the mitral valve has no striking connotations in either a clinical or hæmodynamic sense, except in relation to mitral regurgitation. Simon and Liu (1954) thought that although mitral calcification might be of rheumatic origin, it closely resembles atherosclerotic changes in many respects and further that it may occur as a separate process without the valve itself being involved. However, sclerosis of a tissue that is normally very mobile must in some way influence the hæmodynamics, particularly as autopsy examinations show that calcification, although it may not be visible, may involve the chordæ tendineæ, papillary muscles, and even larger areas (Epstein, 1940). 
Very divergent opinions have been presented recently on the role of mitral calcification in deciding about surgical treatment. Chavez et al. (1955), for instance, have considered calcification of the mitral valve one of the pitfalls of mitral valvotomy. The opinion of Black and Harken (1957) is that although mitral calcification has previously been considered a relative contra-indication, its possible dangerous effects have been greatly reduced by recent developments in surgical techniques: furthermore, as a paradoxical finding, they mention that some of the best results have been achieved in patients with mitral calcification. However, Bailey and Morse (1957) have come to the conclusion that great caution should be exercised whenever calcification is noted. The same conclusion, or perhaps an even more pessimistic view about the influence of calcification, was reached by Winsor (1956) from his study of a series of 645 operations for mitral stenosis. In those patients with calcification the mortality of the operation was over ten times that in other patients of his series, and the rate of unsuccessful valvotomy was about 50 per cent.

The present series leads one only to agree that it is necessary to make as accurate an analysis as possible of mitral calcifications when considering surgery for such patients. This statement applies not only to operations for mitral stenosis, since quite recently a method had been considered for the operative correction of mitral regurgitation (Glover and Davila, 1957). In addition, one must always take into account that typical mitral disease may be accompanied by rheumatic lesions of the aortic valves, which may also include calcification and can be determined only with difficulty by clinical or special methods.

Tomography may also reveal features of other valves that may be of decisive importance when considering the feasibility of surgery. As a practical conclusion from the results of the present study the authors believe that tomograms of each plane of the heart should be recorded in all cases where there are indications for surgery.

Simultaneous tomography is a fairly easy and reliable method compared with radioscopy, which in itself furnishes an instructive dynamic picture but is liable to the shortcomings of subjective methods. In tomograms the shadows of calcification outside the heart are eliminated, and it is relatively easy to determine the site of the valvular calcification from the depth of the image plane. The edges of the calcification are blurred in the tomogram owing to the movement of the valves during the long exposure, but the shadows nevertheless stand out in sharp contrast against the otherwise uniform shadow of the heart, and hence the possibility of erroneous interpretation is slight.

\section{SUMMARY}

Tomographic studies have been conducted using a Siemens Universal tomograph on 68 unselected, consecutive patients with rheumatic valvular heart disease. Calcification of the valve or annulus fibrosus of varying degrees was detected in 24 of them. Two typical cases are described in detail.

The occurrence of calcification did not depend on the age of the patient, except that it was not observed in patients under 30 years. Neither did the incidence of calcification depend clearly on the time that had elapsed since the onset of the rheumatic infection that had caused the valvular damage. Neither the severity nor the extent of the calcification could be correlated with these time factors.

Calcification was relatively more frequent in patients with mitral stenosis, and was most extensive in the mitral leaflets and the annulus fibrosus.

The authors believe that in all patients with mitral disease in whom surgery is contemplated, a complete tomographic examination of the whole heart is necessary before a reliable pre-operative evaluation can be made.

\section{REFERENCES}

Bailey, C. P., and Morse, D. P. (1957). J. thorac. Surg., 33, 427.

Baumann, W. (1936). Münch. med. Wschr. 1114, quoted by Milatz (1956).

Bishop, P. A., and Roessler, H. (1934). Amer. J. Roentgenol., 31, 1.

Black, H., and Harken, D. E. (1957). Amer. Heart J., 53, 439. 
Chavez, I., Vaquero, M., and Mendoza, E. (1955). Acta cardiol., 10, 209.

Epstein, B. S. (1940). Arch. intern. Med., 65, 279.

Glover, R. P., and Davila, J. C. (1957). Circulation, 15, 661.

Hohenner, K. (1940). Fortschr. Geb. Röntgenstr., 61, 16.

Klason, M. L. (1921). Acta radiol. (Stockh.), 1, 162.

Milatz, W. (1956). Fortschr. Geb. Röntgenstr., 85, 282.

Nadas, A. S. (1957). Pediatric Cardiology. W. B. Saunders Co., Philadelphia and London.

Saul, W. (1932). Fortschr. Geb. Röntgenstr., 46, 450.

Simon, M. A., and Liu, S. F. (1954). Amer. Heart J., 48, 497.

Soloff, L. A., Zatuchni, J., and Fisher, H. (1954). Circulation, 9, 367. (1955). Arch. intern. Med., 95, 219.

Sossman, M. C., and Wosika, P. H. (1933). Amer. J. Roentgenol., 30, 328.

Sundberg, C. G. (1941). Acta radiol. (Stockh.), 22, 834.

Winsor, H. M. (1956). Austral. N. Zealand J. Surg., 25, 248.

Wynn, A. (1953). Brit. Heart J., 15, 214. 